\title{
Sonogram features of myxomatous mitral valve disease and abdominal organ dissorders in a senior mini pomeranian
}

\author{
Nindya Dwi Utami ${ }^{1, *}$, Deni Noviana ${ }^{2,3}$ \\ ${ }^{1}$ Biomedical Animal Science, Graduate School, IPB University, Bogor \\ ${ }^{2}$ Cardiology Center Service, Veterinary Teaching Hospital, Faculty of Veterinary Medicine, IPB University, Bogor \\ ${ }^{3}$ Department of Clinic, Reproduction, and Pathology, Faculty of Veterinary Medicine, IPB University, Bogor
}

\begin{abstract}
A 12-years-old mini pomeranian with clinical symptom of coughing was referred to Veterinary Teaching Hospital, Faculty of Veterinary Medicine, Bogor Agricultural University for evaluation. The radiogram showed difus interstitial nodular pattern on the lungs and enlargement of the spleen. Abdominal ultrasonography and echocardiography was performed to further diagnose the dog. Abdominal ultrasonography was taken using linear probe with frequency 5-11 MHz. Echocardiography was perfomed with right parasternal and left apical views using microconvex probe, with frequency 6-8.8 MHz. Abdominal utrasonogram showed that the dog had billiary sludge, mild splenitis, nephrolithiasis, and urolithiasis. Two dimensional Brightness-mode echocardiography showed thickened and prolapsed mitral valve. Two-dimensional M-mode echocardiography showed increasing of left ventricle lumen dimension (LVID) at systole, decreasing of fractional shortening (FS), and enlargement of left atrial. Color Flow Doppler-mode revealed there was mild regurgitation at the mitral valve. These results lead diagnosis to dilated cardiomyopathy and myxomatous mitral valve disease.
\end{abstract}

Keywords:

abdominal ultrasonography, cardiac, mini pomeranian, echocardiography

\section{- INTRODUCTION}

Aging is a biological process which affects many body systems and increases susceptibility to disease. Older animals are at increased risk for diseases such as endocrine dysfunction, renal disease, heart disease, etc. (Shearer 2010). Myxomatous mitral valve degeneration (MMVD) or can be referred as endocardiosis or degenerative chronic mitral valve disease is the most common acquired type of heart disease in older dogs (Noviana et al. 2018, MacGregor 2014). Most dogs affected are clinically asymptomatic for a long time. However, about $30 \%$ of these animals present a progression to heart failure and eventually die as a consequence of the disease (Borgarelli \& Haggstrom 2010).

\section{- METHOD}

A 12-years-old senior mini pomeranian dog was referred to the Veterinary Teaching Hospital, Faculty of Veterinary Medicine, IPB University for ultrasound examinations of the heart and abdomen.

Physical examination performed on the dog before ultrasound examination. Echocardiography was perfomed using microconvex probe, with frequency 6-8.8 MHz. Two dimensional (2D) B-mode and M-mode was taken with right parasternal view, while Color Flow Doppler-mode was taken with left apical view.
Abdominal ultrasonography was performed using linear probe, with frequency 5-11 MHz. The dog was positioned dorsal recumbency. Hair on the examined area were shaved before ultrasound examination performed and ultrasound gel applied in that area before.

\section{- RESULTS AND DISCUSSIONS}

Systolic heart murmur presented in chest auscultation. Systolic murmur at the mitral area is one of the characteristics of MMVD, which increases in intensity as the disease progresses (Petric 2015).
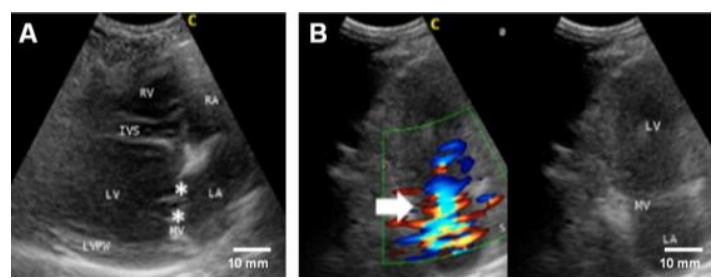

Figure 1 (A) B-mode echocardiogram, right parasternal-long axis view and (B) Color Flow Doppler-mode showed mitral valve regurgitation (arrow). Note: $*=$ thickening and prolapse of mitral valve, $\mathrm{RV}=$ right ventricle, $\mathrm{RA}=$ right atrial, $\mathrm{IVS}=$ intraventricular septum, LV= left ventricle, $\mathrm{LVPW}=$ left ventricle posterior wall, $\mathrm{LA}=$ left atrial and $\mathrm{MV}=$ mitral valve.

Diterima: 10-07-2019 | Direvisi: 05-08-2019 | Disetujui: 15-08-2019

(C) 2019 CC-BY-SA. Ini adalah artikel Open Access yang didistribusikan berdasarkan ketentuan dari Creative Commons Attribution ShareAlike 4.0 International License (https://creativecommons.org/licenses/by-sa/4.0/). 
Figure 1 shows 2D echocardiographic B-mode results in this dog was thickening and prolapse of mitral valve. This results leads to some characteristics of MMVD Myxomatous degeneration is a process that occurs when the valve becomes thickened. This prevents complete closing of the valves and as a result blood can flow backward into the left atrial. The resultant backflow is called mitral regurgitation (MR) (Figure 2). Over time, the atrium and ventricles compensate by enlarging (MacGregor 2014).
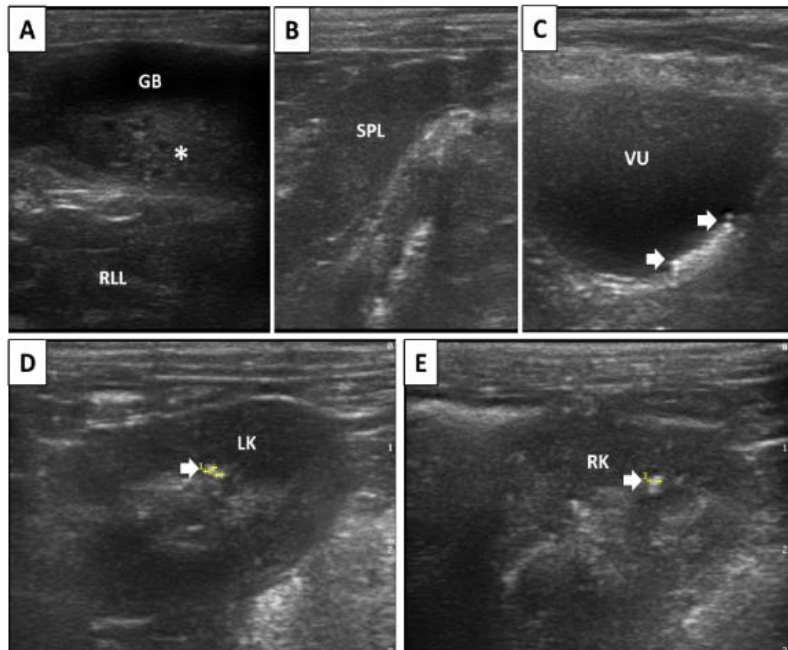

Figure 2 Sonogram of abdominal organs. (A) Billiary sludge $(*)$ in the GB (gall bladder), RLL (right liver lobe); (B) Enlargement of

SPL (caudal spleen); (C) Stones (arrow) in the VU (vesica urinary); (D) Stones (arrow) in the LK (left kidney); and (E) Stones (arrow) in the RK (right kidney).

The 2D M-mode echocardiogram showed an increase in lumen ventricle internal dimension-systole (LVIDs) size and ratio between left atrial appendage-systole and aortic diameter-diastole (LAAs:AoDd) that indicate enlargement of the left ventricle an atrial. The changes of echocardiographic parameters of the dog are shown in Table 1. Furthermore there was a decrease in the value of fractional shortening (FS). Fractional shortening value is important to find out the function of left ventricle, and it is reported to be one of the parameters of dilated cardiomyopathy in dog (Noviana et al. 2018).

Table 1 Heart dimension in 2D M-mode echocardiogram

\begin{tabular}{|l|c|c|c|}
\multicolumn{1}{|c|}{ Parameter } & $\begin{array}{c}\text { Examination } \\
\text { Result }\end{array}$ & $\begin{array}{c}\text { Normal } \\
\text { Value }\end{array}$ & Changes \\
\hline LVIDs (mm) & 17.8 & $8-16$ & $\uparrow$ \\
FS (\%) & 24 & $25-45$ & $\downarrow$ \\
LAAs:AoDd & $1.2: 1$ & $1: 1$ & $\uparrow$ \\
\hline
\end{tabular}

Note: LVIDs= lumen ventricle internal dimension-systole, $\mathrm{FS}=$ fractional shortening, LAAs:AoDd= left atrial appendagesystole and aortic diameter-diastole.

The sonogram of the abdominal organs showed several abnormalities (Figure 2). There was sediment in the gallbladder around $50 \%$, besides that the wall of the gallbladder was rough and thickened $(3 \mathrm{~mm})$. The sonogram also showed some stones in the right kidney, left kidney and vesica urinary. In addition, the tail of the spleen slightly enlarged so that the tip was blunt. Based on the sonogram, it can be diagnosed that the dog had cholecystitis, billiary sludge, nephrolithiasis, urolithiasis, and mild splenitis.

Therapy that can be given to treat the gallbladder isursodeoxycholic acid. Surgery procedures with appropriate option of anesthesia can be done to remove the stones in kidneys and vesica urinary. Therapy for MMVD varies depending on the severity and clinical symptoms. If the MMVD patient is coughing due to heart enlargement, a cough suppressant may be utilized. If congestive heart failures observed, then treatments shouldincludes furosemide, pimobendan, ACE inhibitor and spironolactone (MacGregor 2014).

\section{-CONCLUSION}

The result of echocardiographic examination indicated this dog had myxomatous mitral valve disease (MMVD) and dilated cardiomyopathy. In addition, from the results of abdominal sonogram, it was concluded that the dog had cholecystitis, billiary sludge, nephrolithiasis, urolithiasis, and mild splenitis.

\section{-AUTHOR INFORMATION}

\section{Corresponding Author}

*NDU: nindya.du@gmail.com.

Biomedical Animal Science, Graduate School, IPB University, Jalan Agatis Kampus IPB Dramaga, Bogor, 16680.

\section{Author Contributions}

The manuscript was written through contributions of all authors. All authors have given approval to the final version of the manuscript. All authors contributed equally.

\section{-ACKNOWLEDGMENT}

The authors acknowledge the support from PT Mega Utama Medica for facilitated Q8 Color Doppler Ultrasound to the Veterinary Teaching Hospital, FVM, IPB University.

\section{-REFERENCES}

Borgarelli M, Haggstrom J. 2010. Canine degenerative myxomatous mitral valve diseases: Natural history, clinical presentation, and therapy. Vet Clin Small Anim Pract. 40(4): 651-663.

MacGregor J. 2014. ACVIM fact sheet: Myxomatous mitral valve degeneration. https://www.acvim.org/Animal-Owners/AnimalEducation/Health-Fact-Sheets/Cardiology/Myxomatous-Mitral-

Valve-Degeneration

Noviana D, Aliambar SH, Ulum MF, Siswandi R, Widyananta BJ, Gunanti, Soehartono RH, Soesatyoratih R, Zaenab S. 2018. Diagnosis Ultrasonografi pada Hewan Kecil. Edisi Kedua. Ed. Noviana D. Bogor (INA): IPB Press.

Petric AD. 2015. Myxomatous mitral valve disease in dogs-An update and perspectives. Mac Vet Rev. 38(1): 13-20.

Shearer P. 2010. Literature review-Canine and feline geriatric health. Banfield Applied Research \& Knowledge Team. Banfield Pet Hospital. November 2010. 1-12. 